\title{
Después de Tomochic
}

\author{
Lilián Illades Aguiar \\ Universidad Autónoma de PUERLA
}

\begin{abstract}
1 finalizar el siglo vivió en el noroeste de México una mujer que, según pobladores de Sonora, Chihuahua y Sinaloa, realizaba curacio. nes milagrosas, por ello, se la conocía como la "Santa de Cabora". Su nombre era Teresa Urrea. A continuación se in. tenta reconstruir parte de su historia.
\end{abstract}

\section{CABORA}

En el último tercio del siglo XIX, Cabora era una hacienda ubicada al norte de la ciudad de Álamos, Sonora, y pertenecía a una familia de origen árabe convertida al cristianismo, que se estableció en la costa occidental de Nueva España desde principios del siglo XVIII: los Urrea.

Miguel Urrea, además de ser propie- tario de varias minas de plata en Sonora y Chihuahua, y de la hacienda de Santa Ana en Ocoroni, Sinaloa, adquirió, por su matrimonio con Justina $\mathrm{Al}$ mada, las de Santa Rita de Aquihuiquichi, San Ramón Cocoraqui, San Antonio de Cabora y el rancho de Vizcárraga, convirtiéndose así en uno de los principales terratenientes de Sonora. ${ }^{1}$

Tomás Urrea quedó desde niño al amparo de su tío Miguel Urrea y de su esposa, y fue nombrado administrador de la hacienda de Santa A na; por tal motivo dejó Álamos y se trasladó a Ocoroni. Una vez establecido en su nueva residencia, contrajo matrimonio con una prima hermana: Loreto Echeverri y después de la boda, dejó instalada a su esposa en la ciudad de

1 Domecq, Insólita, 1990, p. 16. 
Álamos regresando él a la hacienda de Sinaloa. Tenía por costumbre establecer relaciones extramaritales con las indias a su servicio. De una relación con una indígena tehueco, llamada $\mathrm{Ca}$. yetana, nació Teresa en Ocoroni, el 15 de octubre de 1873. Fue anotada en el acta bautismal como Niña, García Nona María Rebeca Chávez ${ }^{2}$ y pasó parte de su niñez en Ocoroni; pero, como consecuencia de la oposición de su padre a la revuelta de Tuxtepec, se establecieron en Sonora desde 1888. Ahí, Tomás empezó a administrar la hacienda de Cabora.

Teresa vivió algún tiempo en la ranchería de Aquihuiquichi, cercana a esta hacienda, con su madre y su tía. En 1888 , fue abandonada por Cayetana, $y$ según relató, "mi padre envió por mí para venir a su casa. Fui con él a Cabora". ${ }^{3}$ A partir de ese momento usó el apellido de su padre y el destino de ambos estuvo estrechamente ligado hasta la muerte de él.

La joven de Cabora sufría ataques catalépticos y, durante uno de ellos, fue declarada muerta. Cuentan que estuvo en coma por catorce días, y que posteriormente, desaparecieron sus signos vitales; mas repentinamente se restableció su salud ${ }^{4}$ y a partir de ese momento, entró en un estado de ensimismamiento por tres meses.

Existe un gran número de leyendas sobre las curaciones efectuadas por la llamada "Niña de Cabora" mientras permaneció en trance:

2 Holden, Teresita, 1978, p. 10. Se ignora cuándo se cambió de nombre.

3 Ibid.

${ }^{4}$ Putnam, "Teresa", 1963, pp. 248-249.
Después de su "resurrección" su fama y carácter atrayente iban transformando su casa en un centro para los devotos del "teresismo", indios serranos en su mayoría. Allí se vendían imágenes, medallas y porciones de tierra bendita, con la que se creía poder realizar curaciones milagrosas y hasta revivir personas $y$ animales muertos. 5

Ya sea a favor o en contra, Teresa Urrea fue objeto durante varios años de numerosos artículos periodísticos, tanto en México como en Estados Unidos. Conocía de plantas medicinales por las enseñanzas recibidas de la curandera del lugar desde que era muy pequeña y, aunado a esto, parece que poseía un gran poder hipnótico y una personalidad que irradiaba magnetismo. La conjugación de esos elementos le permitieron combatir las enfermedades físicas o espirituales, reales o imaginarias, de los que la visitaban, ya que contaba con rasgos que la distinguieron de sus contemporáneos y que legitimaron su ascendiente.

Con el tiempo, Cabora y su "santa" cobraron fama. Un reportero de un periódico de Las Cruces, Nuevo México, informó que, en 1891, la hacienda tuvo un promedio diario de 2000 visitantes. Al año siguiente, de acuerdo con El Nacional de la ciudad de México, se habló de 10000 peregrinos. Otras fuentes señalan que por día había 2000 personas en la hacienda. En el

5 Frías, Tomochic, 1979, p. 136. Algunos autores sitúan el primer ataque cataléptico de Teresa cuando ésta recién había cumplido los doce años de edad. Otros, lo sitúan al segundo año de establecerse en Cabora. Holden, Tenesita, 1978, p. 51 . 


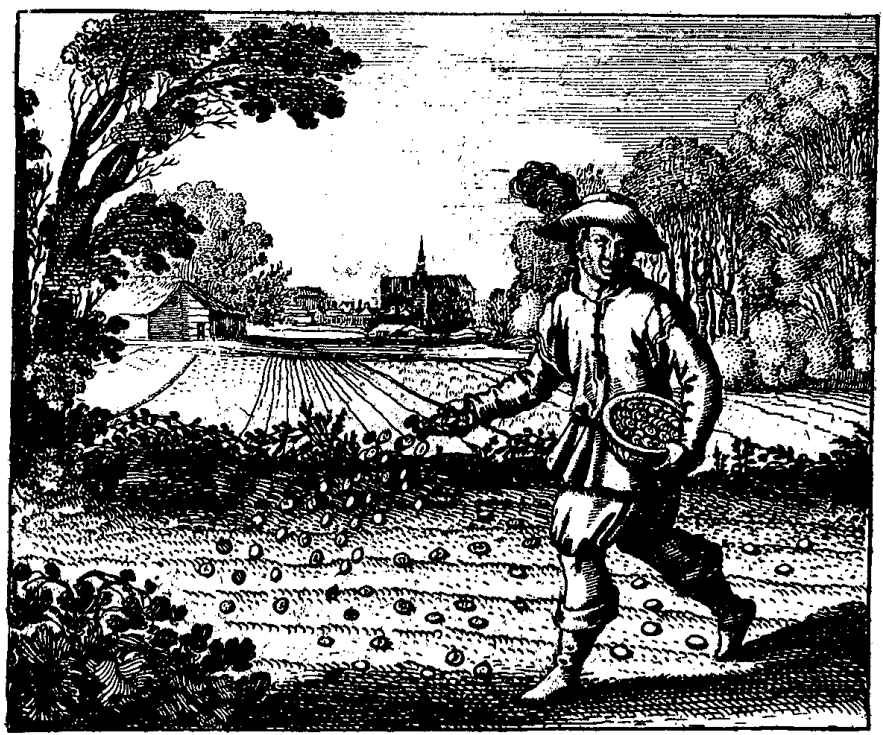

cumpleaños de Teresa, acudían 8000 peregrinos y, sólo durante las fiestas navideñas se congregaban 10000 visitantes. ${ }^{6}$ Es muy probable que el conjunto de esas cifras fuera exagerado, ya que por la distancia se magnificaron los hechos. Sin embargo, fuera cual fuere el número exacto, lo que parece una realidad es que cotidianamente las multitudes arribaban a Cabora.

La mayoría de los fieles de Teresa era pobre e ignorante, por lo que no es de sorprender que esta muchedumbre la visitara, viera en ella a una "santa" y regresara a sus hogares difundiendo sus "milagros". En este caso, la transmisión oral jugó un papel fundamental llevando de boca en boca los prodigios

\footnotetext{
${ }^{6}$ Holden, Teresita, 1978, p. 76.
}

atribuidos a Teresa, entre ellos el don de la profecía, y fueron entendidos como prueba de santidad. El ascendiente de la "santa" era tal, que "el obispo de Sonora, que regularmente bendecía dibujos y pinturas de los santos patronos de sus parroquianos, se quejaba porque cada vez había más gente que trataba de incluir imágenes de Teresa en el montón que iba a consagrar." 7

Se dice que Tomás Urrea, importunado por tanto visitante, renegaba porque, alrededor del nuevo culto, habían surgido puestos de bacanora, de sotol, de albures, de loterías, de fritangas... Una nota de un diario nacional calculó que "Santa Teresa" obtenía considerables dividendos por los servicios presta-

\footnotetext{
7 Vanderwood, "Santa", 1991, p. 38.
} 
$\operatorname{dos}^{8}$ y mientras tanto, la feria de Cabora fue haciéndose famosa y su dueño no pudo frenar el peregrinaje, es más, su propiedad se volvió floreciente. Se tenían que matar diariamente varias reses para alimentarlos, mismas que reaparecían "milagrosamente" vivas al día siguiente. En la hacienda se congregaban enfermos, descontentos, curiosos, espías y reporteros. Estos últimos contribuyeron, con sus escritos, a que los sucesos de Cabora inquietaran al gobierno y al clero porque la hacienda se había convertido en un lugar de reunión que en cualquier momento podría transformarse en un centro de conspiradores.

En diferentes lugares y periodos han surgido personas a las que las masas les han atribuido dotes de santidad debido, parcialmente, a la situación opresiva en que vivian esos pueblos. En épocas de inestabilidad e incertidumbre es un recurso fácil aferrarse $a$ individuos carismáticos a quienes se convierte en líderes mesiánicos por haber obtenido la aprobación de sus coetáneos. Mediante sus prédicas, éstos amortiguaban, un poco, la situación nada segura en que subsistían determinados grupos sociales: marginados, explotados, personas amenazadas por la desocupación, etc. Todos ellos, gracias al líder mesiánico, creían poder encontrar el camino hacia la salvación o, por lo menos, aliviar sus desengaños y aflicciones a través de las prácticas religiosas.

En el norte de México, a finales del siglo XIX, aparecieron por doquier "santos" que contaron con seguidores,

${ }^{8}$ El Monitor Republicano, 13 de febrero de 1892. hecho que tiene que ver con tres sucesos que se registraron en la década de los noventa del siglo pasado: 1 ) el gobierno porfirista despojó a muchos campesinos de sus tierras; 2) la centralización política tocó a poblaciones hasta entonces alejadas de la esfera política nacional y a las que, de manera repentina y violenta, les fueron impuestas autoridades; y, 3) se resquebrajó la economía tradicional ante la llegada de inversiones extranjeras.

Al combinarse esos factores, en ciertas sociedades en que la religión y la política formaban una unidad, se desarrolló un culto en torno a un líder salvacionista. Éste, basándose en su carisma y en su discurso que se orientaba hacia las aspiraciones y requerimientos insatisfechos de sus partidarios, eventualmente condujo a los pueblos a la rebelión.

El año de 1892 fue especialmente dramático para el campo mexicano por registrarse una severa sequía. Gran cantidad de indios mayos, quie. nes habían arrendado sus tierras, no recibieron la renta correspondiente, pues los usufructuarios carecían de recursos para realizar el pago convenido. Hubo indígenas que solicitaron la intervención de las autoridades para resolver el conf licto, y que no obtuvie. ron colaboración de éstas. ${ }^{9}$ Las vicisitudes en la agricultura, aunadas a esta poca respuesta de las autoridades y a los agravios de antaño, provocaron una situación explosiva.

En el mes de mayo, habitantes de las cercanías del río Mayo se sublevaron

9 El Monttor Republicano, 17 de junio de 1892. 
encabezados por Juan Tebas y Miguel Torigoqui. Los doscientos insurrectos atacaron el día 15 las poblaciones de San Ignacio y Navojoa, lanzando vivas a la "Santa de Cabora", pero fueron rechazados por los vecinos y la guarnición de la plaza. Simultáneamente se registraron reuniones desordenadas en varios lugares del río, pero todos los movimientos fueron reprimidos.

Con motivo de los sucesos de Navojoa, El Monitor Republicano denunció a Teresa Urrea como instigadora de la insurrección, dado que algunos indios se refugiaron en Cabora después del ataque al poblado sonorense. Aunque el propietario de la hacienda negó haber escondido las armas de los rebeldes, el periódico capitalino afirmaba que, algunas de ellas, habían sido confiscadas. ${ }^{10}$

El general Abraham Bandala se hizo personalmente cargo de la situación y, el 19 de mayo, al mando de elementos del ejército, llegó a la hacienda de Cabora, de donde hizo salir a Tomás y a Teresa Urrea en calidad de detenidos, juzgando que su presencia en aquel lugar era sumamente lesiva; fueron llevados a Guadalupe y, posteriormente, a Cocorit. Finalmente, el general Bandala, procediendo de acuerdo con el gobernador Rafael Izábal, dispuso el traslado de los Urrea a Guaymas y luego su destierro a Estados Unidos.

La respuesta de Porfirio Díaz a los informes de Bandala hace explícito el beneplácito del presidente por las medidas tomadas por el jefe de la Primera Zona Militar: 1892.

10 El Monitor Republicano, 12 de junio de
México, 7 de junio de 1892.

Gral. Abraham Bandala.

Estimado compañero y amigo:

Atentamente me impuse de su grata de 28 del pasado en que se sirve informarme sobre los acontecimientos que tuvieron lugar hace pocos días en los pueblos del río Mayo, así como respecto de los motivos que originaron ese desagradable motín. Doy las gracias a Ud. por sus detalladas noticias celebrando que todo haya terminado felizmente con la providencia de sacar de Cabora a Urrea y a su hija según el último aviso que me dio Ud. por telégrafo.

Suyo como siempre compañero y amigo afmo.

Porfirio Díaz. ${ }^{11}$

¡Qué lejos estaba Díaz de comprender que la detención y expulsión de los Urrea del país no era un asunto que pudiera considerarse felizmente terminado!

En realidad, no se puede asegurar que Teresa Urrea haya sido la responsable de la revuelta de los mayos, que, creemos, fue utilizada por Abraham Bandala, Rafael Izábal y el presidente Díaz como un excelente pretexto para alejar a los Urrea del país, ya que ellos no podian tolerar que una joven de 18 años enardeciera, mediante sus prédicas, los ánimos de la población indígena y, por consiguiente, alejarla era indispensable. En tres ocasiones, que alcanzaron el carácter de revuelta, el 8649 .

11 Colección Porfirio Díaz (CPD), leg. XXII, f. 
nombre de la "Santa de Cabora" se ha. bía visto involucrado.

Primero fue cuando en 1890 los indios mayos abandonaron sus centros de trabajo para congregarse en la ranchería de Jambiolobampo. A los acontecimientos que ocurrieron ahí se los consideró precursores de insurrecciones. Un segundo momento en que el nombre de Teresa Urrea llegó a los oídos de Díaz fue en diciembre de 1891 , cuando el jefe político del distrito Guerrero de Chihuahua, se enfrentó a los habitantes del pueblo de Tomochic juzgándolos en rebelión. Algunos tomochitecos huyeron del campo de batalla y se dirigieron a Cabora para solicitar el consejo de la "santa", pero no la encontraron. Resulta importante señalar que los serranos creían que, con la ayuda de la "Santa de Cabora" y del Gran Poder de Dios, eran invulnerables a las balas del enemigo. El tercer movimiento en que la "santa" sale a relucir es el motín de los indios mayos en 1892.

En esos tres sucesos se la evocó, lo cual no significa que los movimientos tuvieran como fundamento el fanatismo, como el gobierno quiso hacerlo aparecer ante la opinión pública. Teresa Urrea, voluntaria o involuntariamente, aglutinó a los pueblos que se lanzaron a la lucha para resolver los problemas concretos de la vida y, aunque la religiosidad intervino profundamente, consideramos que actuó como impulso y elemento de cohesión para enfrentar la situación lamentable en que vivían muchos campesinos.

La joven de Cabora se constituyó en un emblema de las reivindicaciones de los desheredados del noreste de México. Posiblemente ella no era plena- mente consciente del potencial que encerraba el culto que le rendian; por lo tanto, no se puede afirmar que la "santa", a través de sus prédicas, indujera de manera deliberada a la sedición y a la herejía. De hecho, no existen testimonios acerca de la responsabilidad de cualquiera de los Urrea en el surgimiento de alguna insurrección. A menos que la pregunta de Teresa: "¿es correcto que el gobierno tome [...] nuestras tierras?" 12 fuera una insinua. ción suficiente para lanzar a los pue blos a la rebelión. Todo parece indicar que, mientras vivió en México, no estuvo a la cabeza de ninguna de las sublevaciones que se le atribuyeron, aunque, no deba dejar de considerarse que la invocación de su nombre haya fortalecido a los rebeldes. Tal vez Teresa y quienes la rodeaban ${ }^{13}$ advirtieron su fuerza hasta que Porfirio Díaz la desterró del país.

\section{EL DESTIERRO}

Es innegable que, para el gobierno, Teresa Urrea era subversiva, de ahí la necesidad de expulsarla del país. Su exi-

12 Putnam, "Teresa", 1963, p. 253.

13 Me refiero a Lauro Aguirre quien nació en el mineral de Batosegachi, cantón Matamoros, Chihuahua. Archivo Histórico Diplomático “Genaro Estrada" de la Secretaría de Relaciones Exteriores (AREM), exp. 9.15-15, s.n.f. De 1880 a 1881 formó parte de la comisión de límites para deslindar los terrenos de Guaymas y Hermosillo. AREM, exp. L-E-730 (I), f. 100 . Se relacionó con los Urrea cuando le solicitaron sus servicios para construir un sistema de riego en la hacienda de Cabora. Aguirre fue protestante y se dice que provocó la modificación de las convicciones religiosas de Teresa. Holden, "Teresa", 1963, p. 12. 
lio pudo deberse a diferentes causas: a la presión ejercida por la jerarquía católica, que veía en sus prédicas una herejí; al interés de las compañías extranjeras por explotar los recursos del noroeste, sin el peligro representado por los indios insurrectos o al creciente poder que la "Santa de Cabora" iba consolidando entre los descontentos de Sonora y Chihuahua. Por ende, Porfirio Díaz aprobó u ordenó su destierro.

En general, los "santos" populares que surgieron en Sonora y Chihuahua en las postrimerías del siglo XIX anunciaron el apocalipsis revolucionario. Tanto el gobierno como la Iglesia católica lucharon permanentemente por silenciarlos y, en algunos casos, tuvieron éxito; pero los predicadores continuaron inflamando los ánimos de muchos campesinos $\mathrm{e}$ indigentes de las zonas urbanas.

Todo parece indicar que Teresa Urrea y Lauro Aguirre impulsaron desde el destierro algunos movimientos en contra del régimen porfirista. Sin embargo, ella siempre negó haber tenido participación alguna en los sucesos de Navojoa y Tomochic. Porfirio Díaz estaba muy lejos de suponer, en el momento de desterrar a la joven Urrea, que su presencia en Estados Unidos iba a alterar aún más, que si la hubiera mantenido en México, a la mal llamada paz porfiriana: la "santa" en el exilio fue un problema mayor que en Cabora.

\section{TUCSON Y NOGALES}

Los Urrea fueron conducidos desde la hacienda de Cabora hacia Cócorit y, posteriormente, a Guaymas. El presi- dente, al ser avisado, recomendó al general Abraham Bandala que procurara "no tener a la Santa cerca de sus tropas porque también son ignorantes y pueden malearse ${ }^{n} .{ }^{14}$ Los detenidos permanecieron incomunicados en tanto abandonaron México y el 2 de junio de 1892, Tomás y Teresa salieron en tren del país al que nunca volvieron. Mientras tanto, Bandala informaba a Porfirio Díaz acerca de su recorrido por el río Mayo, desde Huatabampo hasta $\mathrm{Na}$ vojoa, lugares en donde dejó restablecida la tranquilidad: "la persecución hecha a los indios ha sido tenaz... La lección que han llevado los revoltosos ha sido dura y será difícil que vuelvan a levantarse ${ }^{n} .{ }^{15} \mathrm{~A}$ los indios se les persiguió con crueldad, muchos de ellos fueron enviados o entregados a terratenientes de Oaxaca y Yucatán.

El 3 de junio de 1892 los Urrea se instalaron en Nogales, Arizona. A su llegada, Tomás Urrea pidió protección policiaca de la estación del ferrocarril al hotel en donde se hospedó junto con su hija; así, la pareja de expatriados no pasó inadvertida para la prensa norteamericana. ${ }^{16}$

Cuando la "Santa de Cabora" llegó a Estados Unidos fue objeto de inusitadas demostraciones de asombro y expectación, y aparecieron varios reportajes sobre su arribo donde se la consideró mártir de las injusticias auspiciadas por el gobierno mexicano.

Después de su estancia en el hotel, Teresa y su padre habitaron una casa en Nogales, gracias a una cooperación

\footnotetext{
${ }^{14} \mathrm{CPD}$, leg. $\mathrm{U}, \mathrm{f} .3518$.

15 CDP, f. 3646-3648.

16 AREM, exp. 11-19-11, s.n.f.
} 
realizada por los vecinos del poblado fronterizo; ${ }^{17}$ pero antes de cumplir un mes alli, fueron visitados por Manuel Mascareñas, cónsul del lugar, quien les pidió alejarse de la frontera e internarse más en Estados Unidos. Sin embargo las autoridades locales protegieron a los recién llegados e hicieron ver a Mascareñas que su petición era impropia, pues los Urrea no se encontraban en tierras mexicanas sino norteamericanas. Mas al día siguiente, 25 de junio, padre e hija viajaron a Tucson para solicitar la ciudadanía norteamericana. ${ }^{18}$

\section{BOSQUE Y SOLOMONVILLE}

Tomás y Teresa permanecieron poco tiempo en Nogales y a finales de 1892 se trasladaron a la población de Bosque, a unos $\mathbf{4 0}$ kilómetros de aquella ciudad. Si bien Teresa dejó México, su nombre siguió resonando allí, y así, en 1893, los habitantes de Temosachic del distrito Guerrero de Chihuahua, se rebelaron al grito de ¡Viva la "Santa de Cabora"! El propósito de los sublevados era quitar de su puesto al Supremo Poder de la Nación, ${ }^{19}$ y Temosachic corrió una suerte similar a la de Tomochic. El desorden continuó en el lado mexicano y las invocaciones a la "santa" fueron escuchadas por el presiden. te Díaz.

En octubre de 1895 Tomás y Teresa se mudaron a Solomonville, Arizona, situado aproximadamente a 300 kiló metros de la frontera. Es posible imagi-

\footnotetext{
17 A REM, eXp. 11.19.11, s.n.f.

18 AREM, exp. 9-15-15, s.n.f.

19 Almada, Resumen, 1955, p. 357.
}

nar que se internaran aún más en el territorio norteamericano a causa de alguna amenaza recibida por parte de las autoridades mexicanas. Sin embargo, los disturbios ocurridos durante el siguiente año en la línea divisoria, inducen a pensar que el cambio a Solomonville se efectuó para poder actuar más libremente. Allí no existía ninguna autoridad que representara al gobierno de Porfirio Díaz.

El ingeniero Lauro Aguirre y Manuel Flores Chapa llegaron a Solomonville en el mes de noviembre. El primero de ellos, viejo amigo de la familia Urrea, militó en las filas del grupo lerdista y permanentemente se opuso al régimen porfirista; se exilió voluntariamente poco antes de que Teresa y su padre fueran expatriados. ${ }^{20}$ Aguirre era un hombre informado y con conciencia política y, de acuerdo con Paul J. Vanderwood, era un anarquista que, en esencia, luchó por un país más justo; aunque sus planteamientos no fueron del todo precisos, éstos no dejaban de ser riesgosos para las autoridades. ${ }^{21}$ Flores Chapa también contaba con una tradición de rebeldía. ${ }^{22}$ La casa de los Urrea se convirtió efectivamente, no sólo en el punto de atracción para enfermos y curiosos sino en un centro de conspiración.

${ }^{20}$ AREM, exp. 9-15-15, s.n.f.

21 Vanderwood, “Santa", 1991, p. 36.

22 Manuel Flores Chapa nació en Matamoros, Tamaulipas. A mediados de 1893 se estableció en Brownsville, Texas, donde fundó el periódico El Amigo del Pueblo, que utilizó para atacar al gobierno porfirista. A principios de 1894 se trasladó a Laredo, Texas, población en la que continuó apareciendo su publicación. En 1895 encabezó a un grupo de gente armada que se dirigió hacia Charco Escondido. AREM, exp. LE730 (1), f. 21. 
El 26 de febrero de 1896, el señor Pedro G. de la Loma anunció desde Solomonville, al coronel Miguel Ahumada, gobernador de Chihuahua, la existencia de un documento titulado Plan Restaurador de la Constitución y Reformista, que llegó a manos de Wiley E. James, procurador del condado de Graham, a través del administrador de correos y del editor del periódico La Opinión Pública. Según el procurador, lo elaboraron Lauro Aguirre y un individuo de nacionalidad mexicana, apellidado Chapa, aunque quienes lo firmaron eran residentes de Graham. ${ }^{23}$

El manuscrito al que hacemos referencia, más que un plan restaurador y reformista, es uno de los primeros documentos revolucionarios que se redactaron en contra del gobierno porfirista. Está fechado el 5 de febrero de 1896 en el pueblo de Tomochic. Comienza señalando que, desde la revuelta de Tuxtepec, la Constitución de 1857 había sido constantemente violada y que, en defensa de la paz, se cometieron brutales masacres en diferentes partes del país, entre ellas la de Tomochic; acusa a las autoridades de aplicar la ley "fuga"; denuncia el fraude electoral y el despojo de tierras, particularmente el de las comunales, mediante las compañias deslindadoras; sostiene que el acaparamiento de la propiedad agrícola, en vez de aumentar la riqueza nacional, evita su crecimiento debido a la improductividad de muchas extensiones territoriales: propone la creación de la pequeña propiedad; se opone a la exención de impuestos a los

23 AREM, exp. L-E-730 (I), fs. 41-42. monopolios agrícolas; declara que la tierra, lugar de donde los hombres se proveen de materias primas, tiene que ser de todos y exige que las minas estén al alcance de los trabajadores pobres; acusa al gobierno de no respetar la libertad de expresión y de castigar con rigor y crueldad extrema a los periodistas independientes, además de atentar en contra del resto de las garantías individuales; estima defectuosa la ley electoral vigente por no garantizar el sufragio público y propone una nueva ley que obligue a todos los ciudada. nos a votar; pide una reforma radical de la ordenanza militar para que ésta no esté al servicio de las tiranías; exige la supresión de la pena de muerte y la igualdad entre los hombres; denuncia la relación entre el capital y trabajo como portadora de problemas sociales, y demanda el cese de la explotación del hombre por el hombre; señala como único propósito de los sacerdotes controlar las conciencias de los individuos y vivir del trabajo de éstos; declara que el único medio para sacudir la tiranía de Porfirio Díaz es a través de las armas, último recurso de los pueblos para hacervaler sus derechos, por estar todos los medios legales agotados.

Una vez expuesto lo anterior, el plan desconoce a todas la autoridades federales, estatales y locales del país, responsabilizándolas de la transgresión de la Constitución. Nombra, hasta el triunfo de la revolución, jefe supremo de la República, con atribuciones en los ramos de Hacienda y Guerra, al jefe de la Revolución Restauradora de la Constitución Reformista. Plantea que éste convocará a elecciones una 
vez que hayan transcurrido tres meses de haberse tomado la ciudad de México, siempre y cuando la mayor parte del país esté en manos de los revolucionarios.

El plan, en su parte final, señala que no podría ocupar el cargo de presidente de la República, ni de la Suprema Corte de Justicia el jefe de la Revolución en el momento de lanzarse la convocatoria para la elección de poderes. La prohibición también incluye a cualquier jefe del movimiento revolucionario y a los miembros del ejército regular. Posteriormente, se señalan las funciones de cada estado del país y se otorga a la mujer el derecho de desempeñar cualquier puesto público, incluso el de presidente de la República. ${ }^{24}$

Entre los signatarios del documento sólo hemos podido identificar a Manuel González quien, como veremos más adelante, participó activamente en movimientos armados tendientes a terminar con la administración de Porfirio Díaz. Aparecen también como firmantes, Tomás Echeverri (primer apellido de la esposa de Tomás Urrea) y Mariana S. de Avendaño (mujer que en Cabora visitó a Teresa para que la asistiera en una enfermedad y terminó por convertirse en su inseparable compañera).

La publicación del plan preocupó hondamente al gobierno mexicano. A partir de febrero de 1896 se rumoró sobre la preparación de un movimiento revolucionario que, invocando el nombre de Teresa Urrea "para atraerse adeptos ignorantes[...]",25 habria de

${ }^{24}$ AREM, exp. L.E.730 (1), fs. $102-116$.

25 AREM, exp. L-E-730 (1), f. 13.

realizarse en la frontera mexicano-estadunidense. Lauro Aguirre, quien "conoce mucho esa frontera..." 26 y Manuel Flores Chapa "es de los que están escribiendo contra el Gobierno en San Angelo, Texas,... ${ }^{27}$ Ambos, dejaron desde finales del mes de marzo la población de Solomonville y salieron rumbo a Nogales, Arizona. ${ }^{28}$

El gobierno de México estaba en lo cierto en cuanto a la intención del ingeniero Aguirre de realizar un movimiento revolucionario; tenía noticias de la relación de éste con el coronel "garzista" Rafael Ramírez (uno de los asaltantes del puerto de San Ignacio en Tamaulipas, residente de Roma, Texas, y hombre acaudalado). ${ }^{29}$ Además, sabía que Manuel Flores Chapa había participado con Catarino Garza en actividades subversivas. ${ }^{30}$ Los nexos entre Aguirre y los "garzistas" le hacían pensar, con toda razón, en la posibilidad de que el movimiento que se preparaba se extendiera a lo largo de la frontera. Una carta cifrada confirma claramente la certeza del gobierno en relación a los propósitos de Lauro Aguirre:

Roma, Texas, 7 de febrero de 1896.

Sr. Lauro Aguirre

Solomonville, Arizona

Mi fino amigo:

Tocante al negocio que $U$. me dice de la agricultura no tengo tiempo para explicarle pero por lo pronto cuento con

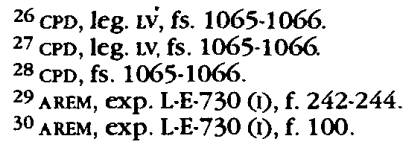


hombres fuertes que me ayuden..., con $100 . .$. , hombres lo menos para el principio del trabajo arreglados con toy (sic.) y armas para el trabajo en mi próxima seré extenso, si U. o algunas otras personas quieren emprender..., el negocio que..., me habla en su carta, se necesita mucho cuidado y tratar los negocios con más exactitud que ninguno otro, porque en esto de la agricultura se necesitan muchos brazos para el trabajo, por no explicarle extensamente del asunto ya sabrá lo que quiero decir. Viva..., cierto y seguro que yo seré de los primeros en ayudar en esa empresa casi, o sin perjuicio de lo que fuera..., quedo a sus órdenes...

Rafael Ramírez. 31

En marzo de 1896 Aguirre y Chapa fueron aprehendidos en El Paso por órdenes de Porfirio Díaz, ${ }^{32}$ bajo el pretexto de que habían infringido las le. yes de neutralidad. ${ }^{33}$ No obstante, por falta de pruebas, quedaron en libertad el 6 de abril siguiente. ${ }^{34}$ Aun cuando no se les pudo acusar del delito de sedición, se les vigiló constantemente. ${ }^{35}$ En la causa instruida contra Aguirre y Chapa el juez Sexton dijo que:

[...]si bien había visto en los acusados bastante predisposición contra el gobierno actual de México, y que de sus declaraciones se habían desprendido marcadas pruebas de su hostil actitud contra la actual administración pública de la república, no por eso encontraba bastante demostrada la responsabilidad

\footnotetext{
31 AREM, exp. L-E-730 (I), fs. 43-44.

32 AREM, exp. L.E-730 (I), f. 13.

33 AREM, exp. L-E-730 (I), f. 28.

${ }^{36}$ AREM, exp. I.E-730 (I), f. 186

35 AREM, exp. L-E-730 (1), f. 186.
}

de conspiración contra la paz pública de México $[. . .]^{36}$

Sin embargo, el juez remitió la causa de los acusados a la Corte de Arizona "en donde quizá con mejores evidencias se demuestre plenamente su culpabilidad y puedan ser castigados si en efecto contravinieron las leyes de neutralidad de los Estados Unidos". 37 A pesar de eso, Aguirre y Chapa empezaron a organizar el movimiento. El primer paso fue el asalto a diferentes aduanas de Sonora y Chihuahua, con el fin de conseguir recursos para financiar su plan y entrar al país. De acuerdo con sus propósitos, después se tomarían el resto de las entidades mencionadas.

\section{El Paso}

En junio de 1896, sin causa aparente, los Urrea dejaron Solomonville e instalaron su nueva residencia en EI Paso, Texas. La noticia fue transmitida por el cónsul Francisco Mallén a la Secretaría de Relaciones Exteriores:

La Santa de Cabora, llegada a ésta el sábado último 13 de junio, está siendo objeto de grande novedad entre nuestra gente del pueblo a ambas márgenes del río Bravo que a visitarla acuden en grandes romerías atribuyéndole cualidades sobrenaturales y venerándola, y la prensa americana ayuda a popularizarla divulgando las curaciones milagrosas que dizque verifica la Santa.

Se trata de una especulación que harán con éxito más que la Santa sus secua-

36 AREM, exp. L-E-730 (1), fs. 124-125.

${ }^{37}$ A REM, exp. L-E-730 (I), fs. 124-125. 
ces, haciendo simpática y meritoria su misión con la persecución que dice la Santa le hace nuestro gobierno.

Activaré su vigilancia comunicándole sus intentos. 38

El propio Mallén, poco tiempo después, se dio cuenta de lo errado de sus suposiciones. Al ser atacadas las aduanas, se comprobố que la "santa" no se mudó a El Paso para especular económicamente. Por otra parte, no faltó mucho para que el mismo cónsul dirigiera la persecución sobre la joven Urrea. Mientras ésta se dedicaba a atender a cuantos la iban a ver, Aguirre se entregó a la conspiración en la ciudad fronteriza, ${ }^{39}$ lugar estratégico para dirigir el movimiento porque se podría introducir, desde ese punto, a los grupos armados y comprar pertre. chos de guerra.

Cuando las autoridades de El Paso habían declarado ya a Lauro Aguirre y Manuel Flores Chapa sin responsabilidad alguna en el delito de violación de las leyes de neutralidad entre Estados Unidos y México, apareció en aquel poblado un semanario redactado por Aguirre. Según Pedro B. López, informante del cónsul de Laredo, "el general Terrazas de Chihuahua da una subvención al [...] Independiente [...] en el cual se postula para gobernador del Estado de Chihuahua". "No hemos encontrado ningún testimonio que compruebe lo anterior. Desde su comien. zo, el semanario había a atacado al gobierno mexicano y poco a poco, según informó Tito Arriola, jefe político

\footnotetext{
38 Valadés, Porfirio, 1985, pp. 79-80.

39 CPD, leg. Iv, f. 3564.3570 .

40 AREM, eXp. L-E.730 (I), fs.2.246.
}

del distrito Bravos de Chihuahua, "ha venido insolentándose al grado de que hoy es ya un verdadero cartel de injurias y calumnias [contra Díaz]... Dicho papel es subversivo y excita al pueblo a la revolución. ${ }^{n 1}$

En los números iniciales de la publicación apareció el relato de los hechos que habían tenido lugar durante la rebelión de Tomóchic de 1891-1892. Uno de sus primeros editoriales presentó a Teresa Urrea como una mujer que había dedicado toda su vida a ha. cer el bien y no obstante era perseguida y cazada por el gobierno mexicano. El Independiente fue un órgano de di. fusión que manifestó claramente su oposición al régimen porfirista y sus redactores no desperdiciaron ningún pedazo de papel para hacer patente su predisposición al gobierno mexicano. En cada edición apareció una nota que decía: "Anúnciese en El Independiente, periódico de la mayor circulación por estar su circulación prohibida por Herodes, El Necesario y los frailes." 42

Los conspiradores se reunieron en El Paso. La insurrección debía de estallar el 8 de agosto de 1896 en Ciudad Juárez, Ojinaga, Palomas y Nogales. ${ }^{3}$ Ese día, varias partidas de hombres armados cruzaron la frontera y se internaron en las sierras de Sonora y Chihuahua. En Ciudad Juárez, el movimiento fracasó por la rapidez con la que actuó el jefe político del distrito Bravos. ${ }^{44}$

${ }_{11} \mathrm{CPD}$, leg. Xxt, f. 12414-12416.

42 AREM, exp. 1.3-670 (1), f. 67.

43 Archivo General de la Nación (AGN), Colec. ción Manuel González, vol. 8, f. 352.

44 AGN, Colección Manuel González, vol. 8, fs. 350-351. 


\section{ADUANAS DE OJINAGA Y NOGALES}

Demetrio Cortés, al mando de 19 hombres, llegó al municipio de Ojinaga el 7 de agosto de 1896, situándose en la sierra de Pegüis el día 14. Diez fiscales y el mismo número de vecinos de Coyame se enfrentaron en El Álamo con el grupo rebelde y lo derrotaron, aunque éste, de nueva cuenta, combatió en El Nogal. ${ }^{45}$ Al ser vencidos, Cortés y sus hombres se refugiaron en Esta. dos Unidos. ${ }^{46}$ La celeridad con la que obró el gobierno seguramente obedeció al mensaje enviado por el presidente de la república al gobernador de Chihuahua: "es necesario que esa gavilla desaparezca, procediendo con la mayor actividad." 47 A partir de ese mo. mento, quedó vigilada toda la frontera del estado de Chihuahua. ${ }^{48}$ La derrota sufrida por los "teresistas" -nombre con el que se denominaba a los grupos que atacaron las aduanas-en la población de Ojinaga, no impidió que Pomposo Ramos Rojo y Benigno Arvizu, al frente de aproximadamente cuarenta "indios yaquis y según parece tomochis $[\ldots]^{n}, 49$ entraran a la plaza de Nogales en la madrugada del 12 de agosto al grito de "VViva la Santa de Cabora!" 50

El comandante de la Tercera Zona de la Gendarmería Fiscal, Juan Fenochio, fue informado de que los asaltantes habían ocupado las calles de la po-

45 Ibid., f. 308.

46 CPD, leg. LV, fs. $4667-4669$.

${ }^{47}$ AGN, Colección Manuei González, vol. 8, fs. 224-225.

48 CPD, leg. Lv, fs. $4524-4527$.

49 AREM, 1-3-670 (n), fs. 1-5.

${ }^{50} \mathrm{AGN}$, Colección Manuel González, vol. 8, fs. 227-228. blación, tomando el dinero que estaba en la Aduana. Fenochio, en compañía de los cuatro gendarmes que se encontraban en el lugar, abrió fuego sobre los asaltantes que pronto tomaron la ofensiva. El tiroteo duró varias horas hasta que los "teresistas", cargando su botín, se retiraron a las afueras del poblado. Al día siguiente volvieron a enfrentarse con el resto de la gendarmería, que no había participado en el tiroteo de la noche anterior. ${ }^{51}$ Por la tarde llegó a Nogales un grupo compuesto de 70 mexicanos y americanos que acudieron al llamado de auxilio del cónsul de Nogales, Arizona, Manuel Mascareñas. Los "teresistas" fueron dispersados en la madrugada y, finalmente, cruzaron la línea divisoria. 52

En los periódicos El Imparcial y $E l$ Oasis de Nogales se denunció como promotores del asalto a la Aduana a Teresa Urrea y a Lauro Aguirre:

El Oasis de Nogales: Todo indica que el presente ataque es la largamente anunciada revolución de don Lauro Aguirre. Todos los bandidos muertos en la refriega traían copias de El Independiente, periódico de Aguirre y a uno se le encontró un retrato de la Santa de Cabora y, una carta en español que a la letra dice:

"Acuérdate que el 11 de agosto es el día que irás a Nogales. Tomarás el pue blo y te vengarás. Acuérdate que Santa Teresa está siempre contigo y que por medio de su milagrosa influencia nin. gún daño os podrá ser hecho." 53

Teresa Urrea fue acusada abiertamente por algunos periódicos como

51 Ibid., fs. 261-262.

52 Ibid., fs. 227-228.

53 Ibid., f. 342. 
instigadora del asalto a las aduanas, "la gente ignorante y fanática la cree mandada por Dios para redimir al mundo y sobre todo a la República Mexicana" ${ }^{54}$ Para las autoridades de México, los "teresistas" aparecían como gavillas de fanáticos y bandidos. ${ }^{55}$ Ella nunca aceptó la acusación que se le hizo y, el 21 de agosto de 1896, apareció en el semana. rio El Independiente un largo artículo titulado "Mis ideas sobre las revoluciones", signado por aquélla. En primer término, Teresa negó que ella o Aguirre hubieran participado, directa $o$ indirectamente, en los sucesos fronterizos. Señaló que éstos no eran los únicos disturbios que, contra el gobierno porfirista habían tenido lugar en el país durante los últimos meses y dijo que:

[...] esos movimientos revolucionarios obedecen a un profundo descontento público contra el despotismo del gobierno y que lo racional, lo justo y lo lógico es suponer que lo de Nogales obedece a las mismas causas que los muchos movimientos de México, y no a mí, porque es estúpido creer que en veinte movimientos revolucionarios habidos en un pais, diez y nueve obedezcan a una causa, al descontento público, y uno de ellos, esté fuera de esa causa. 56

Posteriormente, hizo una amplia disertación justificando la necesidad de las revoluciones. En el texto manejó conceptos filosóficos e históricos que hacen suponer, por su escasa educación, que el escrito más bien se debió a la pluma del ingeniero Aguirre. A ve-

${ }^{54}$ AREM, exp. $1 \cdot 3-670$ (1), f. 37.

55 AREM, exp. 11:19-11, f. 36 .

${ }^{56}$ AGN, Colección Manuel González, vol. 8, fs. 271-277. ces, se exime a la "santa" de cualquier responsabilidad en relación con el movimiento revolucionario de Lauro y consideran que éste la utilizó para su causa. Sin embargo, es difícil pensar que Teresa fuera totalmente ajena a los planes de su amigo o que estuviera en su contra. De ser así, no hubiera permitido que el artículo apareciera a su nombre. Pero de allí no se deduce que Teresa se entregara a la conspiración en la misma medida que Lauro. Por el contrario, es factible suponer que el ascendiente que la "Santa de Cabora" tenía sobre los pobres, le sirvió a Aguirre para alentar su movimiento.

Los fracasos de Ojinaga y Nogales no frenaron a los "teresistas". Las investigaciones llevadas a cabo por los agentes consulares de México en las poblaciones fronterizas indicaron que Lauro Aguirre, Teresa Urrea y su grupo de partidarios continuaron dedicados a la conspiración. La situación a lo largo de la línea divisoria era tan delicada que el gobierno de México pidió la colaboración de las autoridades de Estados Unidos para acabar con los organizadores de los asaltos.

De las averiguaciones norteamericanas se desprende que Teresa Urrea proporcionó a sus seguidores ayuda económica. Además, bendijo sus armas, les manifestó que no debían temer por sus vidas, ya que ella los protegería orando por el triunfo del movimiento y les entregó un escapulario y su retrato. ${ }^{57}$

Sobre la fotografía de la "santa", el señor C. A. Rose dirigió el 7 de septiembre de 1896 una carta a Francisco

57 CPD, leg. xxa, fs. 16788-16792. 
Mallén, cónsul de México en El Paso, en la que afirmó que tenía pendiente un negocio con la señorita Urrea, relativo a la producción y venta de sus re. tratos. Teresa solicitó que en cada uno se imprimiera al reverso, en inglés yen español, una copia del texto "Juana de Arco". El manuscrito le fue presentado por Lauro Aguirre, editor de un periódico en El Paso, quien dijo estar autorizado para el caso. El fotógrafo informó al cónsul que se entrevistó con Tomás Urrea auxiliado por un intérprete, ya que temía que la reproducción del texto al reverso de la fotografia tuviera cuestiones que lo comprometieran o resultaran inconvenientes para las autoridades mexicanas. Urrea le sugirió no firmar los retratos. Por último, el fotógrafo aclaró que escribió al cónsul para que lo orientara porque en los principales diarios aparecían los nombres de Urrea y Aguirre complicados en recientes trastornos públicos. ${ }^{58}$

Rose adjuntó a la carta una copia del escrito que le fue entregado para su edición. El manuscrito tenía por título: "Señorita Teresa Urrea, Juana de Arco mexicana" y contenía algunos de sus datos biográficos. También, hablaba de sus facultades para curary de sus cualidades morales. El escrito finalizaba señalando que Teresa fue desterrada por:

[...] el crimen de practicar el bien [...] y la opinión pública la ve como la única persona capaz de cambiar la faz de México, sacudir la tiranía del gobierno que asesina sin formar causa, a sus enemigos, que incendia pueblos, que extingue como negrero razas, que da amnis-

58 AREM, exp. 11-19.11, f. 26. tía y después mata, que degüella niños, $[$...] Por creerse que ella derribará al gobierno actual y hará al pueblo mexicano cambiar su situación política se la ve como la Juana de Arco mexicana. El mismo gobierno de México lo cree así, por la tenacidad con que la persigue. 59

Todo incriminaba a la joven Urrea y a Lauro Aguirre como conspiradores.

El 25 de septiembre de 1896, el juez de distrito de Sonora, Pedro A. Magaña, integró el testimonio de las diligencias practicadas con motivo del asalto a la Aduana de Nogales. El expediente consta de numerosas declaraciones que en conjunto explicitan la participación de Lauro Aguirre y la "santa" en la organización del atraco. ${ }^{60}$ Asimismo, a los asaltantes se les encontró entre otras cosas, un papel que decía:

Hermanitos: no dejen de alistarse para el día 11 porque vamos a pegar el grito luego que lleguemos, no tengan miedo; luego tenemos que entrar en Sonora, por eso les digo que se alisten todos ustedes; yo voy a llegar en la noche a Nogales porque no se puede menos. La Pazy la ley sean con ustedes. Teresa Urrea y Juan Bautista. 61

Ninguno de los autores intelectuales del robo se presentó esa noche en Nogales por el fracaso de la operación. No obstante, los preparativos para el nuevo golpe siguieron adelante, según los informes proporcionados por Juan A. Hernández, jefe de la segunda zona militar, al presidente de la república:

\footnotetext{
59 AREM, exp. 11-19-11, fs. 27.29.

${ }^{60}$ AREM,exp. $1-3-670$ (d), fs. 6-56.

${ }^{61} \mathrm{AGN}$, Colección Manuel González, vol. 8, fs.
} 322.336. 
Se sabe que en la casa de Teresa Urrea [...], hubo reunión a la que asistieron 7 u 8 mexicanos, el padre de ella y Lauro Aguirre, éste tomó la palabra excitando a los concurrentes a imitar lo acontecido en Nogales y citándolos para una próxima reunión en la misma casa. 62

\section{AdUana de Palomas}

El gobierno mexicano responsabilizóa los Urrea y a Lauro Aguirre de los sucesos de Nogales e inició las gestiones necesarias para solicitar su extradición. Mientras tanto, los intentos revolucionarios de los "teresistas" continuaron en marcha. El juez de distrito de Ciudad Juárez, B. Frías Camacho, notificó el 4 de septiembre al cónsul mexicano en El Paso que en esa ciudad se realizaron reuniones de carácter sedicioso entre Lauro Aguirre, los Urrea, Ricardo Johnson (hijo), Benigno Arvizu, Pomposo Ramos, Antonio Vizcarra e Ignacio Morales. ${ }^{63}$

A principios de septiembre de 1896 ya estaban organizados dos nuevos grupos que habrian de penetrár al territorio mexicano para asaltar la aduana de Palomas. A diferencia de los anteriores asaltos allí no se luchó al grito

$62 \mathrm{CPD}$, leg. XXI, f. 13843.

63 CPD, leg. xxI, f. 13294. Ricardo Johnson, padre e hijo, eran originarios de Sonora. Llegaron a El Paso, Texas, en agosto de 1896. Johnson (hijo), aparecía como editor y redactor responsable de El Independiente. AREM, 1-3-670 (I), f. 67. A Porfirio Díaz se le informó que Johnson (padre) "ha traído algún dinero y asume un carácter más formal que Iauro Aguirre". Acerca de Johnson (hijo) se le hizo saber que "tiene más prestigio y es según parece el que está organizando con mejor éxito trabajos en contra de este país". CPD, leg. XXI, f. 12603-12604. de "iViva la Santa de Cabora!" El día 14, un grupo de $\mathbf{4 0}$ hombres armados "con sharp calibre $45-60$ de caballería e infantería del ejército de Estados Unidos[... $]^{n 64}$ atacaron la población encabezados por Pomposo Ramos Rojo, Demetrio Cortés y Manuel González (a éste último le llamaban Cruz Chávez, no sólo por su participación en la rebelión de Tomochic sino porque, según las noticias publicadas en los periódicos de la época, se decía que tenía gran parecido con el "Papa Máximo" de Tomochic. González era blanco, alto, barbado, viejo vaquero y gran cazador). 65

Los "teresistas" ocuparon el caserio y tomaron los pocos fondos con que contaba la Aduana. Finalmente, se internaron en Estados Unidos. ${ }^{66}$ De acuerdo con el New York MorningJournal, entre los asaltantes había indígenas de Tomochic y alguna gente blanca. ${ }^{67} \mathrm{Po}$ co tiempo después, Demetrio Cortés fue apresado y declaró que "su plan. era pelear con los gobiernos federal y del estado[...], por restricciones de onerosas leyes hacendarias". ${ }^{68}$ Cuan-

64 AREM, exp. 9-15-14, f. 1. Desconocemos el medio a través del cual, los "teresistas" consiguieron armas del ejército norteamericano. La posesión de éstas permite suponer básicamente tres cuestiones. En primer término, que las armas fueron robadas. En segundo lugar, la existencia de contrabando y, por último, aunque nos parece una conjetura aventurada, el apoyo brindado por Estados Unidos a los rebeldes para causar problemas al gobierno vecino. Sin embargo, no contamos con ningún testimonio que nos sirva para sostener cualquier de las conjeturas esbozadas.

65 AREM, exp. 15.7.26, f. 232.

66 AGN, Colección Manuel González, vol. 8, f. 223.224.

67 ARFM, exp. 15.7.26, f. 24.

${ }^{68} \mathrm{AGN}$, Colección Manuel González, vol. 8, f. 352. 
do se realizó el ataque a Palomas, como para los autores intelectuales existían más posibilidades de derrota que de triunfo, se pidió a los asaltantes que no mezclaran a Teresa Urrea en el asunto e hicieran hincapié en los altos impuestos.

\section{LA EXTRADICIÓN}

El asalto a Palomas ocasionó que el gobierno de México multiplicara la vigilancia a lo largo de la frontera y que se intensificara la persecución a Teresa Urrea, a su padre y a Lauro Aguirre. Fueron 16 los "teresistas" aprehendidos por las autoridades americanas. A Demetrio Cortés, Prisciliano González Silva, más otros dos hombres, el gobierno federal de Las Cruces, Nuevo México, los sentenció a dos años dos meses de prisión y un dólar de multa porviolar las leyes de neutralidad. Tres quedaron libres por falta de pruebas en su contra; Pomposo Ramos Rojo y el resto de sus compañeros permanecieron detenidos mientras se reunieron los requisitos indispensables para solicitar su extradición. 69

Ramos Rojo declaró ante el notario público William E. Baker del condado de Doña Ana, Nuevo México, que en el verano de 1896, estando preso en la cárcel de Hermosillo, recibió cartas de Lauro Aguirre y los Urrea, en las que lo exhortaron a huir de la cárcel para que los ayudara en los asaltos que preparaban a lo largo de la frontera. Ramos, fugándose de la penitenciaría se trasla. dó a El Paso, gracias a la ayuda econó-

$69 \mathrm{lbid}$., fs. 224-225. mica que aquéllos le suministraron. En esa población fue llevado a casa de Teresa Urrea y ahí le informaron de los movimientos que se llevaban a cabo en El Pegüis al mando de Demetrio Cortés, Francisco Salas y Manuel González. También señaló que en casa de Teresa Urrea se celebraron varias reuniones antes y después del asalto a Nogales. Por último, dijo que entre Lauro Aguirre, Teresa Urrea, Ricardo Johnson y él prepararon una cuadrilla para atacar la Aduana de Palomas. Las provisiones y municiones usadas las proporcionaron los dos primeros. ${ }^{70}$

El 9 de octubre de $1896 \mathrm{el}$ promotor fiscal de Estados Unidos en El Paso, Duval West, notificó a Roberto V. Culberson, procurador general de esa nación:

La penuria de los secuaces de la Teresa y su consiguiente impotencia para comprar armas, equipos, caballos $[\ldots]$ ha sido en realidad, el único impedimento que ha habido para que las fronteras mexicanas no fueran invadidas por un gran número de ellos. ${ }^{71}$

Los planes revolucionarios de los "teresistas" no se alcanzaron, entre otras cosas, por la cooperación aportada por las autoridades de Estados Unidos al gobierno mexicano en la persecución y aprehensión de los rebeldes, impidiendo al movimiento alcanzar la dimensión anhelada por los conspiradores. Posiblemente, las condiciones necesarias para el derrocamiento del gobjerno porfirista aún no estaban maduras. Si bien se contaba con gente pobre dispues-

\footnotetext{
${ }^{70}$ AREM, exp. 9-15-14, fs. 8-29.

${ }^{71}$ AREM, exp. 11-19-11, f. 58.
} 
ta a participar en una lucha en contra de la dictadura, se carecía del apoyo de la clase media, cuya intervención fue decisiva en la revolución de 1910.

El gobierno de México, a través de su cónsul en El Paso, activó las gestiones para lograr la extradición de los Urrea, de Aguirre y de algunos de sus más próximos seguidores. De ahí que Díaz manifestara a Luis E. Torres, gobernador de Sonora: "Si resulta culpabilidad de la Santa, de su querido (se refiere a Lauro Aguirre) o de su padrastro (alude a Tomás Urrea) se pida su extradición si procediere, en caso contrario su castigo por atentado contra las leyes de neutralidad o a lo menos su internación. ${ }^{72}$ En caso de no autorizarse la extradición, el régimen porfirista estaba dispuesto a utilizar cualquier recurso para castigar "convenientemente" a Teresa Urrea por creeria responsable de los asaltos a las aduanas de Ojinaga, Nogales y Palomas, registrados en el año de 1896:

Nogales, septiembre 4 de 1896.

Señor Presidente

General Porfirio Díaz

México.

Al terminarse averiguación por asalto Nogales hay elementos para pedir extradición Urrea.

Nuestras gestiones deben tener efecto seguro, pues puede ocurrir que la extradición se denegara o que concedida no se verificara por algún golpe de mano de los ilusos que rodean a la Santa.

Por otra parte, considerando todas

${ }^{72}$ CPD, leg. Lv, fs. 4808.4809 . las molestias que traería al gobierno el proceso de la Urrea, el escándalo que promoviera por los antecedentes de esta mujer, las delaciones que sus de. fensores podrían causar en el juicio y la posibilidad de que pudieran salvarla de una sentencia condenatoria se me ocurre que la mejor solución al asunto sería encontrarle algún giro convenien. te a fin de que se condujera a la acusada a esa capital y previo reconocimiento médico se le consignara a un asilo de mujeres dementes que es a donde le corresponde estar según las muestras que ha dado de desequilibrio cerebral.

El Gobernador: Luis E. Torres. ${ }^{73}$

El presidente, por su parte, respondió lo siguiente:

México, septiembre 17 de 1896.

General

Luis E. Torres

Al darle las gracias por los nuevos informes que contiene (su grata del 4 de sep. tiembre) y por las oportunas indicaciones que me hace, le manifiesto que se tendrá presente su idea sobre Teresa Urrea una vez que esté en nuestro poder, pues en efecto su ingreso al manicomio procede de plano.

Porfirio Díaz. ${ }^{74}$

A pesar de las numerosas gestiones realizadas por las autoridades de México para lograr la extradición de los inculpados en los asaltos a las aduanas, los planes del gobierno porfirista fracasaron. La extradición no se obtuvo

73 CPD, leg. Xxa, f. 16331.
${ }^{74}$ CPD, leg. Xx, f. 16333. 


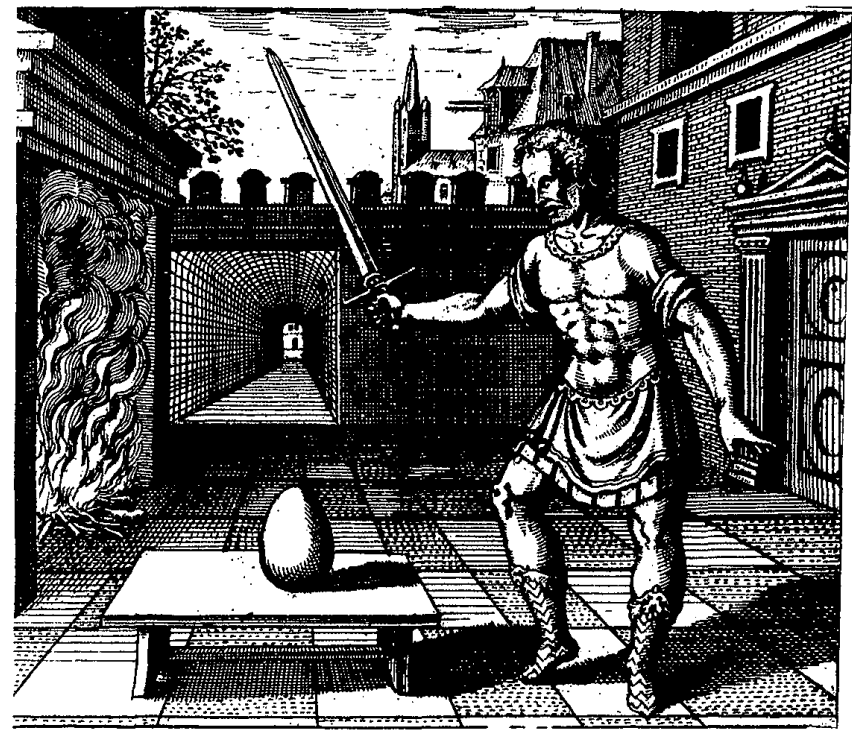

porque los Urrea ya habían solicitado la ciudadanía americana y "el gobierno de Estados Unidos no extradita a sus nacionales [...]". ${ }^{75}$ Además, no se encontraron "pruebas materiales que puedan servir para fundar la requisitoria de extradición". ${ }^{76}$ Tampoco se pudo lograr que Teresa regresara a México mediante pretexto alguno, aunque las autoridades mexicanas hicieron hasta lo imposible por repatriarla.

En lo que se refiere a Aguirre y a sus compañeros no se consiguió nada, por la negativa del gobierno norteamericano para autorizar la extradición, ya que los delitos eran de carácter político y no estaban incluidos en los trata-

${ }^{75} \mathrm{CPD}$, exp. 9-15.15, s.n.f.

${ }^{76} \mathrm{CPD}$, leg. XXI, f. 16382.16385. dos celebrados entre México y Estados Unidos. ${ }^{77}$ Por tal razón, el cónsul Mallén preparó una trampa en contra de Aguirre a fin de que declarase su complicidad en los últimos acontecimientos ocurridos en México. La treta no dio el resultado deseado y el incidente fue aprovechado por el ingeniero para denunciar en su periódico, al concluir el año de 1896, que habían tratado de secuestrarlo. Al poco tiempo de ese suceso, Aguirre aseguró en El Independiente que agentes del consulado mexicano estuvieron a punto de asesinar a Teresa Urrea, en virtud de que un individuo intentó agredirla. ${ }^{78}$

El cónsul Mallén, al enterar a la Se-

77 AREM, exp. 9-15-15, s.n.f.

78 Valadés, Porfirio, 1985, pp. 95-98. 
cretaría de Relaciones Exteriores sobre lo sucedido a la joven Urrea, negó haber tomado parte en el asunto, pero es factible suponer que mintió pues, al parecer, él comulgaba con ese tipo de maniobras. Años más tarde procedió de igual forma con el propio Aguirre y los hermanos Flores Magón, cuando en 1906 pretendieron tomar Ciudad Juárez. ${ }^{79}$ De haber sido cierto el atentado, éste tenía como propósito atemorizar a Teresa y obligarla a abandonar El Paso. Tres meses después de lo ocurrido, en el verano de 1897, Teresa y su padre se trasladaron a Clifton, Arizona.

\section{CLIFTON}

Los Urrea se alejaron de la frontera y, en su nueva residencia, se retiraron a la vida privada. En el pueblo minero de Clifton, Tomás estableció un aserradero y una lechería, ${ }^{80}$ mientras Teresa continuaba prestando sus servicios a los enfermos, pero el gobierno de México aún no estaba convencido de que fuera inofensiva. De tal suerte que, en octubre de 1899, un minero llamado Guadalupe Rodríguez, enviado por las autoridades mexicanas para terminar con ella, según declaró Teresa años después, se presentó en su vida y, en junio de 1900 , contrajeron matrimonio. Como Teresa descubrió la verdadera intención de su esposo, se alejó de él. Cuatro años más tarde, consiguió el divorcio en California. ${ }^{81}$ Concluido este episodio, el señor Charles Rosencrans, ofreció a la

79 Ibid.

80 Putnam, "Teresa", 1963, p. 258.

81 Holden, Teresita, p. 1978, pp. 176-177. "santa" un trabajo de enfermera en California, en casa de unos amigos de él. ${ }^{82}$ Teresa dejó Clifton en 1900, sin sospechar que nunca volvería a ver a su inseparable compañero: su padre. Tomás Urrea murió en septiembre de 1902.

En San José, California, ella atrajo la atención de reporteros que publicaron extensos artículos acerca de la "Santa de Cabora". La propaganda de los diarios San Francisco Examiner y San Francisco Chronicle, entre otros, hicieron que una compañia médica norteamericana, que se interesó en la joven Urrea, le propusiera la realización de una gira por la Unión Americana y Europa para promover a la empresa y, a la vez, descubrir el origen de los "poderes" de la "santa". Teresa aceptó el ofrecimiento y recorrió varias ciudades norteamericanas. ${ }^{83}$ Así, en 1901, declanó al periódico Saint Louis Post Dispatch:

Estamos en un recorrido por el mundo para conocer la fuente de mis poderes, si es posible. Algunos manifiestan que provienen directamente de Dios. Otros dicen que son el resultado de alguna peculiaridad nerviosa o psíquica. Incluso otros pretenden que soy la médium de un personaje presumiblemente un espíritu. No sé. Los teósofos dicen que algún cuerpo astral está manifestándose a través de mí. Cualquier cosa que sea, vino a mí mientras estaba en trance. He curado a miles y espero curar miles más. Iré a París, a Oberammergau [sic], a Jerusalem, a la India y de ahí a Egipto. Quizá en algún lugar es probable que encuentre a alguien sabio en tales asuntos quien pueda decirme el secreto. ${ }^{84}$

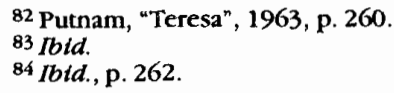

$83 \mathrm{Ibld}$.

Ibid., p. 262 
En ese mismo año, estando Teresa en St. Louis Missouri, solicitó a su amiga Juana Van Order, residente de Solomonville, Arizona, le enviara a uno de sus hijos para que hiciera las veces de intérprete. A pesar de haber residido varios años en Estados Unidos, no hablaba inglés. John Van Order, menor que ella algunos años, llegó a su lado. Teresa y John vivieron juntos. En Nueva York, tuvieron a su primera hija, Laura, que nació en el año de 1902. Allí acabó el contrato con la compañía médica sin que Teresa cumpliera su sueño de llegar a Europa. Regresó a Solomonville, sitio en el que nació su hija Magdalena en 1904.85

Los años que trabajó para la empresa norteamericana le permitieron, al dejar Solomonville y volver a Clifton, construir un lugar en donde siguió atendiendo enfermos. ${ }^{86} \mathrm{El} 11$ de enero de 1906, Teresa Urrea murió de tuberculosis en Clifton, a los 33 años de edad. A mediados de ese mismo año se publicó el Programa del Partido Liberal Mexicano en St. Louis Missouri y el incansable ingeniero Aguirre para ese entonces ya se había integrado al magonismo.

En 1906 el gobierno de México seguía gestionando la extradición de Lauro Aguirre. Nunca la logró, no obstante el tratado de reciprocidad propuesto por las autoridades de este país. ${ }^{87}$ Todavía en 1911 Aguirre no cejaba en su añejo propósito de poner fin a la dictadura de Porfirio Díaz, sumán-

\footnotetext{
85 Domecq, "Teresa", 1984, pp. 166-167.

86 Holden, Teresita, 1978, p. 180.

87 AGN, Colección Manuel González, vol. 30 ,
} f. 64 . dose a las luchas revolucionarias de los magonistas. ${ }^{88}$ Murió el viernes 9 de enero de 1925. Durante dos décadas combatió al gobierno porfirista como conspirador de movimientos armados y como periodista de oposición. ${ }^{89} \mathrm{El}$ ingeniero Aguirre y Teresa Urrea bien podrían sumarse a la lista de precursores de la revolución mexicana.

\section{BIBI.IOGRAFÍA}

-Almada, Francisco R., Resumen de historia del estado de Chihuahua, Libros Mexicanos, México, 1955.

-Chávez, José Carlos, Peleando en Tomochi, $3^{2}$ ed., Centro Librero La Prensa, Chihuahua, 1979.

-Domecq, Brianda, "Teresa Urrea La Santa de Cabora" en Temas sonorenses a trat'és de los simposios de historia, Gobierno del Estado de Sonora, Hermosillo, 1984, pp. 139-169.

, La insólita historia de la

Cabora, Planeta, México, 1990.

-Frías, Heriberto, Tomochic, Prólogo de J. W. Brown, 4⿳亠丷厂 ed., Porrúa, México, 1979 (Sepan Cuantos..., 92).

-Holden, William Curry, Teresita, Stemmer House, Maryland, 1978.

-Putnam, Frank Bishop, "Teresa Urrea, the saint of Cabora", en The Southern California Quarterly, Historical, vol. xtv, núm. 3, septiembre 1963, pp. 245.264.

- Valadés, José C., Porfirio Díaz contra el gran poder de Dios, Leega-Júcar, México, 1985.

-Vanderwood, Paul J., "La santa batalla de la niña de Cabora" en La Jornada Semanal, nueva época, núm. 111, 23 de julio 1991 , pp. 34-40.

$$
\begin{aligned}
& 88 \text { AREM, exp. L-E-623 (I), f. } 43 . \\
& { }^{89} \text { La Patria, } 9 \text { de enero de } 1925 .
\end{aligned}
$$




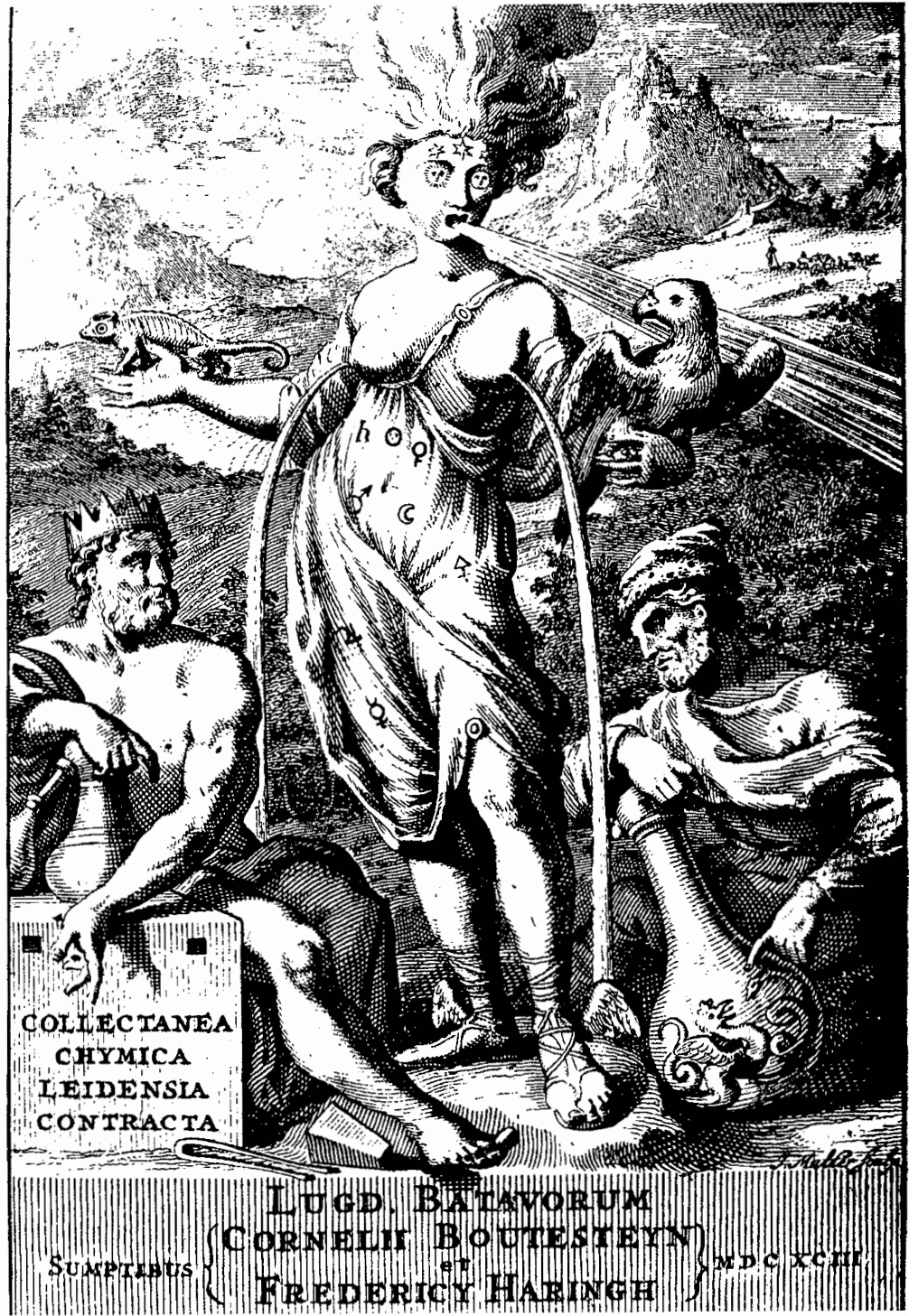

